\title{
Duke Cancer Institute
}

National Cancer Institute

\section{Source}

National Cancer Institute. Duke Cancer Institute. NCI Thesaurus. Code C39393.

The Duke Cancer Institute is dedicated to a broad spectrum of cancer research and the translation of that research into the latest in patient care. The Center serves as the focus for all of Duke University's activities in cancer, a single entity that integrates and aligns patient care and research with the goals of improving patient outcomes, decreasing the burden of cancer and accelerating scientific progress. It became an $\mathrm{NCl}$-designated comprehensive cancer center in 1972. 